\title{
Investigation of Influencing Parameters for Tribological Conditions in Dry Forming Processes
}

\author{
Jennifer Steiner $^{1} \cdot$ Marion Merklein $^{1}$
}

Received: 30 June 2015/Revised: 28 October 2015/Published online: 9 December 2015

(C) The Chinese Society for Metals and Springer-Verlag Berlin Heidelberg 2015

\begin{abstract}
Environmental awareness and a growing demand for efficient resource utilization encourage the realization of lubricant-free forming processes. A first step in accomplishing dry sheet metal forming is to gain knowledge about the changing tribological conditions and to identify the relevant influencing parameters. The commonly used flat strip drawing test was selected to investigate the tribological conditions in the flange area of deep drawing processes. The influencing factors of contact pressure and varying drawing velocities were analyzed under dry and lubricated conditions. Additionally, the tool and workpiece surfaces were characterized. Besides lubrication, the contact pressure mainly determines the tribological conditions. In lubricated tests higher normal pressure reduces friction, whereas without lubrication higher pressure results in slightly increasing friction. A changing drawing velocity affects the friction when lubricant is applied. In dry experiments, no influence of velocity was found. Results of surface characterization reveal adhesion as main wear mechanism under dry conditions. Based on the investigated influence of the process parameters, an increase in process understanding for dry forming operations is derived.
\end{abstract}

\section{KEY WORDS: Deep drawing; Tribology; Friction; Dry forming}

\section{Introduction}

Global trends like increasing ecological awareness influence sheet metal forming industry. Environmental protection measures concentrate on green production technologies and ecofriendly products. Decreasing the use of environmentally harmful materials can be achieved by realizing lubricant-free forming operations. So-called dry forming processes lead to a greener production and more efficient usage of resources since the disposition of oil and detergents is eliminated. Furthermore, the number of

Available online at http://link.springer.com/journal/40195

\section{Jennifer Steiner}

jennifer.steiner@fau.de

1 Institute of Manufacturing Technology, Friedrich-AlexanderUniversität Erlangen-Nürnberg, Egerlandstraße 13, 91058 Erlangen, Germany production steps is reduced because there is no necessity of cleaning and drying of the workpiece before subsequent production steps like painting or welding [1]. However, in lubricant-free processes, the direct contact between tool and workpiece results in a strong interaction accompanied by increasing friction and extensive wear [2].

Besides the elimination of lubricants, the use of lighter materials for sheet metal forming parts is preferable to manufacture ecofriendly products. Therefore, the number of parts made out of aluminum alloys is constantly increasing in the automotive industry during the last decades. Main advantages are beneficial material properties like high strengths associated with low density [3]. In order to combine the environmental advantages of dry forming processes and lightweight materials, this study concentrates on elementary investigations for the lubricant-free deep drawing of parts made of aluminum alloy. Some basic investigations about dry deep drawing in general have been conducted by Kataoka et al. [4]. In context with aluminum 
alloys, approaches to realize dry forming operations often concentrate on tool-sided diamond-like carbon (DLC) coatings to reduce friction [5]. However, basic investigations about the changed tribological conditions in a lubricant-free contact are rare. Therefore, the aim of this study is to analyze the tribological system by strip drawing tests under dry and lubricated conditions with varying process parameters. Knowledge about the tribological changes and influencing parameters under dry conditions is necessary to find the right measures to control friction and wear. As workpiece material, the aluminum alloy AA6014 is investigated.

\section{Experimental}

\subsection{Test Setup}

Diverse types of strip drawing tests are available to model the friction in the different areas of a deep drawing process. In this paper, the flat strip drawing test is selected as laboratory test in order to investigate the friction coefficients and wear mechanisms in the flange area. The test setup mirrors the tribological conditions between blank holder and die during a deep drawing process. Therefore, flat strip drawing tests are commonly used when analyzing friction in the flange area of sheet metal forming operations [6]. Figure 1 depicts the schematic test setup containing an upper fixed and a lower movable friction jaw and a sheet metal strip between the friction jaws. When the distinct normal force $F_{\mathrm{N}}$ is applied, the strip is drawn through the friction jaws. The drawing force is measured and is equivalent to the friction force $F_{\mathrm{F}}$. The friction coefficient $\mu$ is determined according to the Coulomb friction law where $\mu$ is proportional to the friction force $F_{\mathrm{F}}$ and the normal force $F_{\mathrm{N}}$. In general this friction law is valid under dry conditions without plastic deformation of the

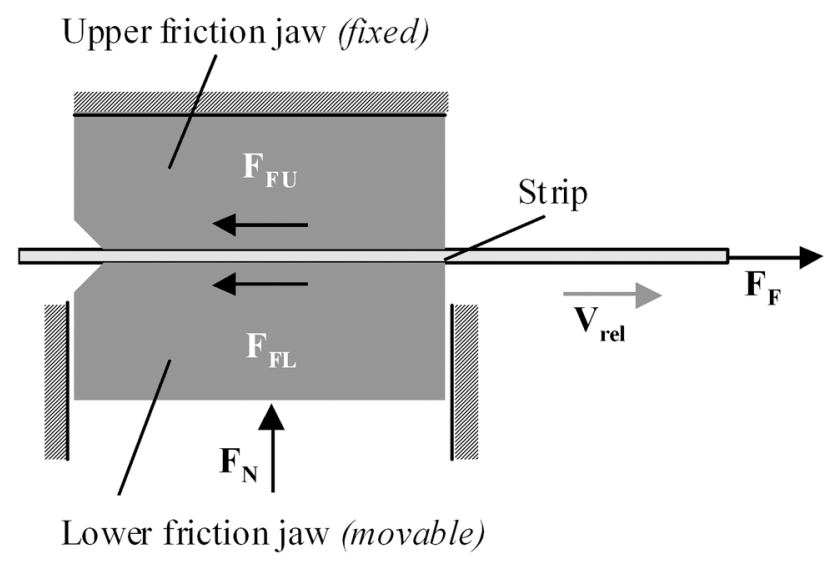

Fig. 1 Schematic diagram of the setup of flat strip drawing test contacting partners [7]. However, due to its simplicity and widespread availability, it is commonly used also in lubricated sheet metal forming processes [8].

\subsection{Experimental Design}

The investigated tribological system consists of the friction jaws and the sheet metal strips. Figure 2 shows the dimensions and the initial surface topography of tool and workpiece. The strips out of AA6014 have a sheet thickness of $1 \mathrm{~mm}$ and an electrical discharge textured (EDT) surface. In general, 6xxx Al alloys are widespread used for outer panels in car manufacturing because of their good formability and high surface quality [9]. The strips are cut with the TruLaser Cell 7020 from Trumpf to a width of $65 \mathrm{~mm}$ and a length of $500 \mathrm{~mm}$. As tool material the cold working steel X155CrVMo12 (1.2379) is selected. The friction jaws have a width of $55 \mathrm{~mm}$ and a length of $100 \mathrm{~mm}$. The friction jaws are ground and subsequently finished by combined lapping and polishing with oil-based diamond suspension with a grain size of $9 \mu \mathrm{m}$. Thus, grinding marks are removed and an undirected surface structure reveals as depicted in Fig. 2a.

The strip drawing tests are performed under dry and as reference under lubricated conditions. To protect the strip surface during transport and storing, an anticorrosive lubricant was applied from the aluminum manufacturer. Hence, all strips are cleaned with acetone to remove this basic lubrication. An oil film sensor based on infrared spectroscopy is used to measure if the lubrication is completely removed. For the lubricated test series, the deep drawing oil KTL N 16 is applied manually with a foam roll. According to standard oil film thickness for producing car body parts, the film thickness was defined to $m=2.0 \mathrm{~g} / \mathrm{m}^{2}$ [10]. Former studies have shown that mainly influencing parameters on tribological behavior with lubrication are contact pressure, drawing velocity and lubricational conditions [11]. Thus, velocity and normal pressure are varied in three steps for the lubricated and the dry tests. The chosen parameters are presented in Table 1. The normal pressure is varied between 1.0 and 2.0 MPa which represents typical load conditions in the flange area of deep drawing processes [12]. In forming processes the drawing velocity is typically set in a range of $100 \mathrm{~mm} / \mathrm{s}$; therefore, the values for relative velocity are defined to be 50,100 and $150 \mathrm{~mm} / \mathrm{s}$.

\section{Results}

\subsection{Friction Coefficients}

The friction coefficient is determined as average value between the drawing lengths from 100 to $170 \mathrm{~mm}$, where 
(a) Friction jaw

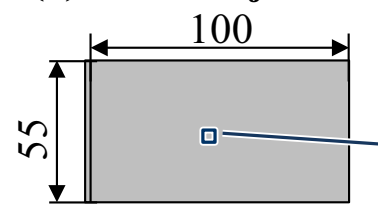

(b) Strip AA6014

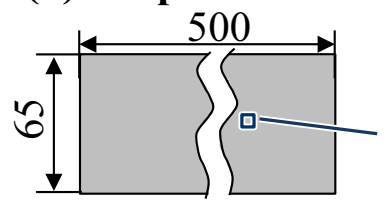

\section{Drawing direction}

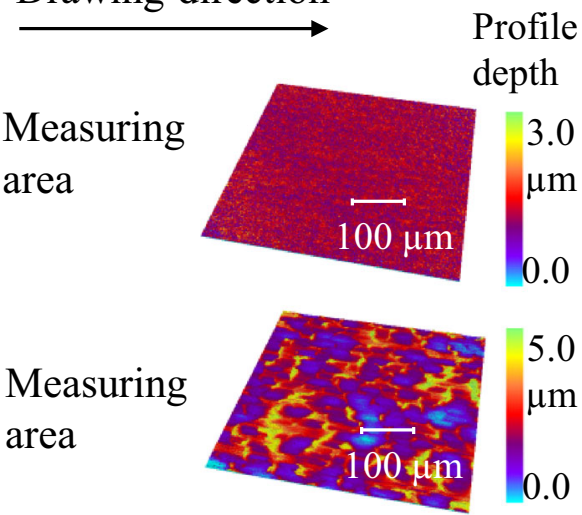

$$
\begin{aligned}
& \text { Confocal microscopy } \\
& \text { Lens }=20 \mathrm{x} / \quad \text { Alignment }=2^{\text {nd }} \text { degree polynomial }
\end{aligned}
$$

Fig. 2 Dimension and initial topography of friction jaw $\mathbf{a}$ and sheet metal strip $\mathbf{b}$

Table 1 Experimental design and test parameters $\left(n_{\text {AA6014 }}=3\right)$

\begin{tabular}{ll}
\hline Velocity $V_{\text {rel }}(\mathrm{mm} / \mathrm{s})$ & 50,100 and 150 \\
\hline Normal Pressure $p_{\mathrm{N}}(\mathrm{MPa})$ & $1.0,1.5$ and 2.0 \\
Lubricational condition & Lubricated with $2.0 \mathrm{~g} / \mathrm{m}^{2} \mathrm{KTL} \mathrm{N} 16$ and dry condition \\
\hline
\end{tabular}

constant sliding conditions can be assured. For each parameter combination three strips are drawn. A new pair of friction jaws is used for each test series. Figure 3 presents the results of the strip drawing tests. Comparing the friction coefficients, it is obvious that the main influencing factor is the lubricational condition. Without lubrication the friction coefficients rises to an approximately 20 times higher level. The reason is the intensive interaction between tool and workpiece when there is no separating oil film. Analyzing the lubricated tests, there are distinct influences for the varied parameters. The lowest friction coefficient of 0.014 reveals at a high pressure of $2 \mathrm{MPa}$ and a low velocity of $50 \mathrm{~mm} / \mathrm{s}$. The maximum value of 0.036 is reached at $1 \mathrm{MPa}$ contact pressure and $150 \mathrm{~mm} / \mathrm{s}$. The high viscosity of $160 \mathrm{~mm} / \mathrm{s}^{2}$ of KTL N 16 in combination with low contact pressure prevents that the lubricant is squeezed out of the contact zone. Therefore, hydrodynamic lubrication, which is characterized by very low friction coefficients, is one of the dominating friction regimes in this case. During hydrodynamic conditions, the friction force increases with increasing drawing velocity, because the internal friction inside the oil film increases [13]. This effect can be observed in Fig. 3 by comparing friction coefficients at the different levels of relative velocity. Besides the drawing velocity, the friction depends on the contact pressure. With an increasing normal pressure, the
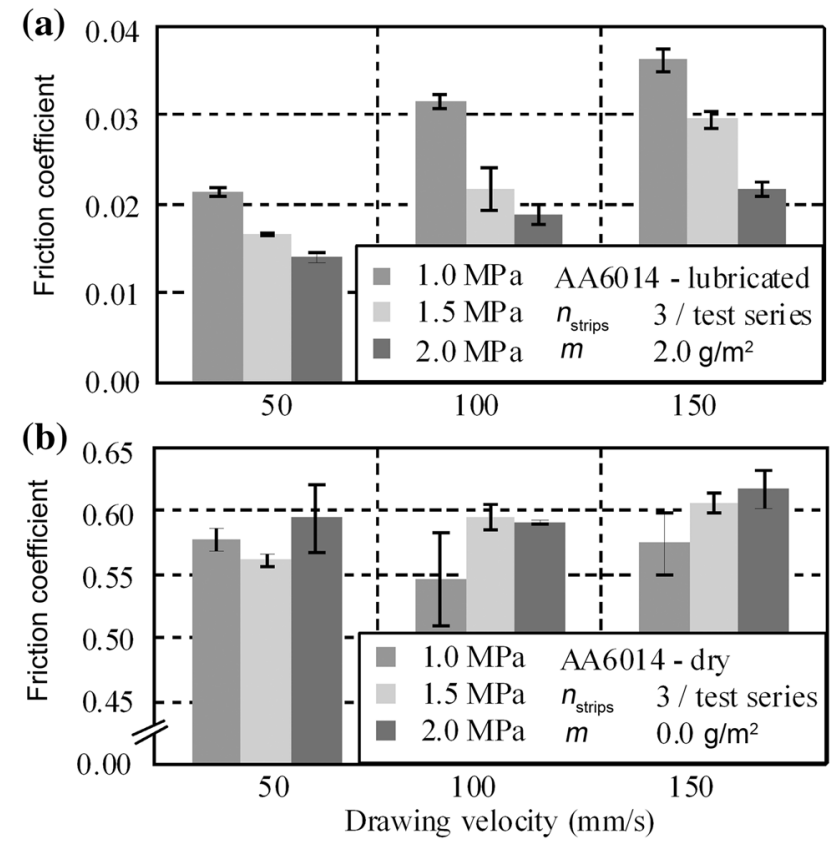

Fig. 3 Resulting friction coefficient under a lubricated and b dry conditions

friction coefficient is decreasing under lubricated conditions. This effect can be observed for all drawing velocities. At higher contact pressure, the sheet surface is 
increasingly flattened. Therefore, the oil is pressed out of the lubricant retaining pockets building a more stable and homogenous oil film between friction jaws and strips. The influences of the varied parameters for the dry test series are not as evident as for the lubricated ones. Without lubrication the lowest friction coefficient of 0.54 is achieved at $1 \mathrm{MPa}$ contact pressure and $100 \mathrm{~mm} / \mathrm{s}$ drawing velocity. The maximum friction coefficient of 0.61 reveals at $2 \mathrm{MPa}$ and $150 \mathrm{~mm} / \mathrm{s}$. The friction coefficient is slightly increasing with a rising contact pressure. At a higher level of normal force, the interlocking between the roughness peaks of the sheet material and the tool increases. When the shear stresses at the contacting asperities exceed, the material strength of the contacting partner with the lower tensile strength adhesion occurs. Thus, with increasing normal pressure, wear in terms of adhesion increases and leads to rising friction. A changing drawing velocity seems to have no obvious influence on the development of the friction coefficient. For the test series with $1 \mathrm{MPa}$ contact pressure, the friction coefficient is decreasing when the velocity is increased from 50 to $100 \mathrm{~mm} / \mathrm{s}$. For the relative velocity of $150 \mathrm{~mm} / \mathrm{s}$, the friction level is nearly the same as for $50 \mathrm{~mm} / \mathrm{s}$. Therefore, at very low pressure, a changing velocity has no distinct influence on the friction. Comparing the friction development for the test series at 1.5 and 2.0 MPa pressure, the friction is slightly increasing with an increasing drawing velocity. However, there is no significant influence of the drawing velocity under dry conditions.

Comparing the friction coefficients of dry and lubricated tests, it is disclosed that for dry experiments a higher deviation reveals. In addition, the influences of the varied parameters are not as distinct as under lubricated conditions. In lubricated experiments, the contact conditions are constant over the number of drawn strips. In contrast, without lubrication the contact conditions change considerably during drawing the first strip. The direct contact causes immediate occurrence of adhesion as described in Fig. 4 and thus changes the surface properties. According to the von Mises yield criterion, the yield strength is reached above the maximum friction coefficient of 0.577 which causes plastic deformation. In the dry
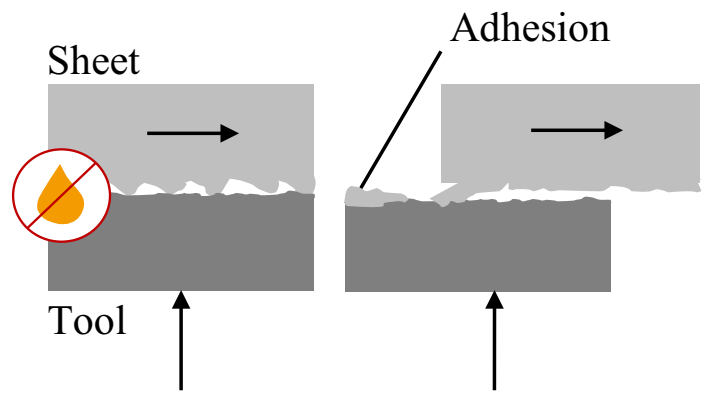

Fig. 4 Schematic diagram of the wear mechanism under dry conditions with aluminum alloys tests, the mathematically determined friction coefficients exceed this level of 0.577 . Thus, it has to be taken into account that the drawing force $F_{\mathrm{D}}$ determining the friction coefficient $\mu$ is the sum of friction forces and deformation and shearing forces which are caused by interlocking of roughness asperities, as schematic shown in Fig. 4.

Wang et al. [14] indicated that under dry conditions the Coulomb friction law is valid until a maximum pressure level, even when plastic deformation occurs. Therefore, to analyze the parameters influencing the tribological behavior, the comparison of the mathematically determined coefficients reveals reasonable. Figure 5 exemplarily depicts the drawing force-drawing length curve for the dry test series with a contact pressure of $2 \mathrm{MPa}$ and a velocity of $50 \mathrm{~mm} / \mathrm{s}$. For strip No. 1 the running-in behavior is characterized by an increase in friction force from 8 to $16 \mathrm{kN}$ during the first $45 \mathrm{~mm}$. At this part of the experiment, the initial interaction between tool and sheet leads to starting and increasing adhesion. Afterward, a constant drawing force is reached. The progression of the drawing force of strip No. 3 reaches a stable value after $10 \mathrm{~mm}$. The adhesion on the friction jaw after strip No. 1 leads to a different area of real contact for the following strips. Thus, the real contact pressure is changing over the number of drawn strips although a constant normal force is applied.

\subsection{Surface Properties}

The surface characterization has been performed prior and after the tests for the strips and the friction jaws. The optical measuring has been done with a NanoFocus " $\mu$ surf" confocal microscope. When using a lens with $20 \times$ magnification, the measuring area of one single picture has a size of $0.8 \mathrm{~mm} \times 0.8 \mathrm{~mm}$ compared to the total contact area of $100 \mathrm{~mm} \times 55 \mathrm{~mm}$. Thus, only a very small measuring field can be analyzed. Therefore, a methodology to

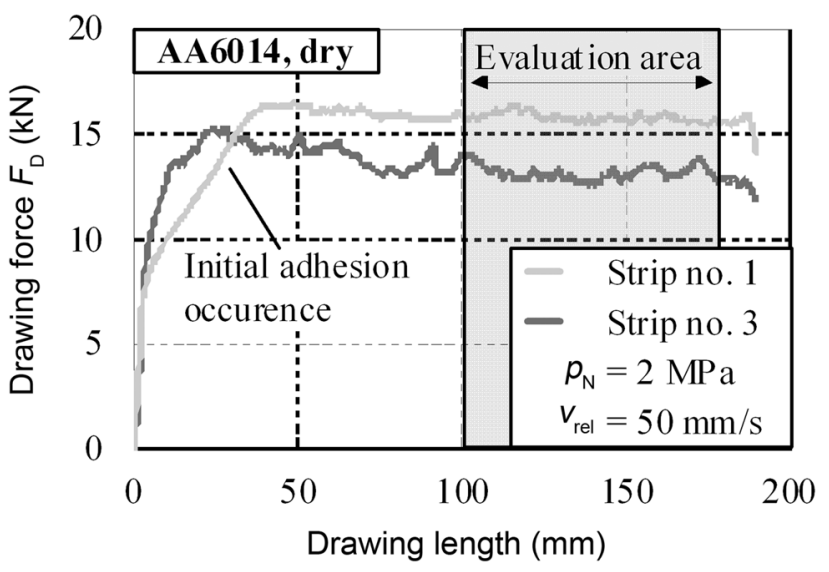

Fig. 5 Comparison of drawing force-drawing length curve for strips No. 1 and No. 3 
evaluate wear mechanisms of the total contact area was developed. As already known from former investigations of aluminum casting alloys under dry sliding conditions, adhesion occurs as main wear mechanism [15]. Thus, the strip material is transferred to the surface of the friction jaws. The tool steel and the adhesive aluminum particles have different reflection properties of visible light. Thus, all friction jaws are photographed after the experiments. Image processing techniques in MATLAB were used to quantify the areal adhesion as depicted in Fig. 6. By using a thresholding operation, all pixels of the grayscale image are converted depending on their gray value into black or white pixels. Thus, the bright adhesion zones can be identified by counting the amount of white pixels in the thresholded image. To compare the different jaws, the areal percentage of adhesion on the tool surface is calculated.

The frictions jaws applied in the lubricated tests reveal no adhesion. In contrast, for the dry experiments, $5 \%-15 \%$ of the tool surface shows distinctive wear. Figure 7 depicts the correlation between friction coefficient and areal percentage of adhesion on the tool surface for the lubricant-free test series. With increasing galling, the resistance to sliding motion increases because of rising bonding forces. This results in higher friction forces and thus leads to increasing friction coefficients. Hence, to realize dry forming processes with aluminum sheets, the adhesion affinity between tool and workpiece material needs to be reduced.

Figure 8 shows the resulting surface properties of friction jaws and sheet metal strips after the experiments with a drawing velocity of $100 \mathrm{~mm} / \mathrm{s}$ for the three levels of contact pressure without lubrication. In addition, the friction coefficient for the first strip is shown for the three test series. Only slight wear in terms of $4 \%$ areal adhesion occurs at a normal pressure of 1.0 MPa where the lowest friction coefficient is achieved. The photograph as well as the topography of the tool surfaces shows distinctive wear for 1.5 and $2.0 \mathrm{MPa}$ where approximately $10 \%$ areal adhesion can be obtained. The intensive interaction between tool and workpiece results not only in rising wear and friction coefficients but in scratches on the sheet surface. Comparing the sheet topographies in Fig. 8b, an

Photography Transferred Computing percentage of tool surface to black/white amount of white pixels

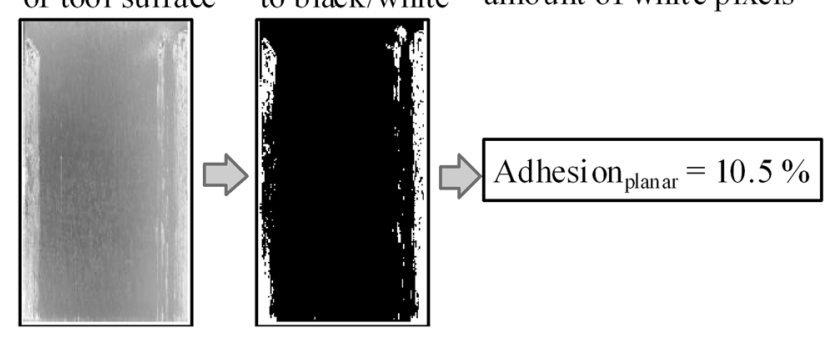

Fig. 6 Evaluation of areal percentage of adhesion

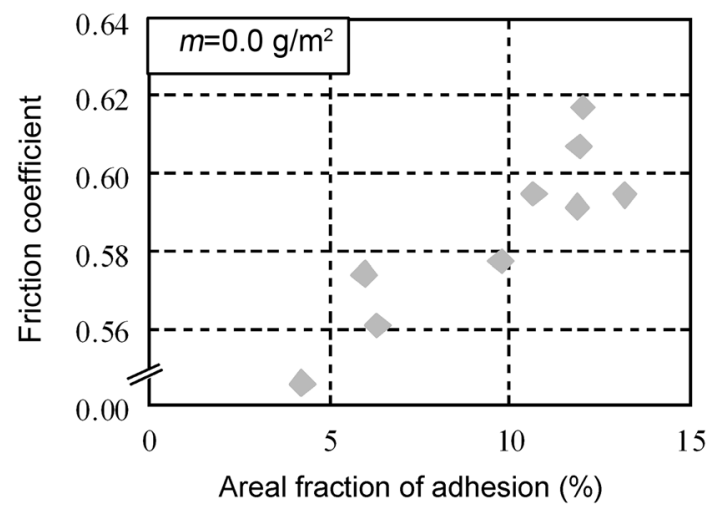

Fig. 7 Correlation of friction coefficient and areal percentage of adhesion under dry condition

increasing contact pressure leads to progressively flattened sheet surfaces. To quantify this effect, the value for the closed void volume $V_{\mathrm{cl}}$ is analyzed. With a decreasing $V_{\mathrm{cl}}$, the surface is smoother and thus the volume of lubrication retaining pockets is reduced. Applying a contact pressure of $2.0 \mathrm{MPa}$ leads to an approximately three times lower volume of closed valleys compared to $1.0 \mathrm{MPa}$ normal load. A smoother sheet surface results in increasing true contact area which increases the target area for adhesion occurrence. Therefore, the friction coefficient for the first strip reaches a level 0.5 for the lower pressure in connection with slight adhesion and reaches a maximum of 0.61 for high pressure and strong adhesion.

The intensive interaction resulting from the direct contact under dry conditions leads to roughening of the tool surface. Figure 9 compares the initial surface properties with those after the dry test series. For each measuring area, three measurements were performed. The optical measuring was conducted in the center of the friction jaw surface. In order to evaluate galling, the edge areas of the friction jaws were measured as shown in Fig. 8. To analyze the topography, the measuring parameter $S_{\mathrm{pk}}$ was selected. A higher value for the reduced peak height $S_{\text {pk }}$ indicates higher roughness peaks which result from adhesive particles. The values for $S_{\mathrm{pk}}$ in the center of the contact area are not significantly changing. The reason for the concentration of adhesion in the edge area might be found in the constructional design of the test rig. The lower friction jaw is mounted on a spherical ball, which assures a parallel alignment during the drawing. However, the first contact before the spherical ball aligns the surfaces is often located out of the friction jaw center. Under dry conditions this initial unbalanced contact results in a local flattening of the sheet surface and thus determines the further propagation of adhesion. Therefore, the edge area reveals increasing values for $S_{\mathrm{pk}}$. The reduced peak height $S_{\mathrm{pk}}$ in the edge area and the areal adhesion is rising with increasing contact pressure. Thus, the microscale measuring by confocal 


$$
\mathrm{p}_{\mathrm{N}}=1.0 \mathrm{MPa}=1.5 \mathrm{MPa} \quad=2.0 \mathrm{MPa}
$$

(a) Tool surface and topography after three strips
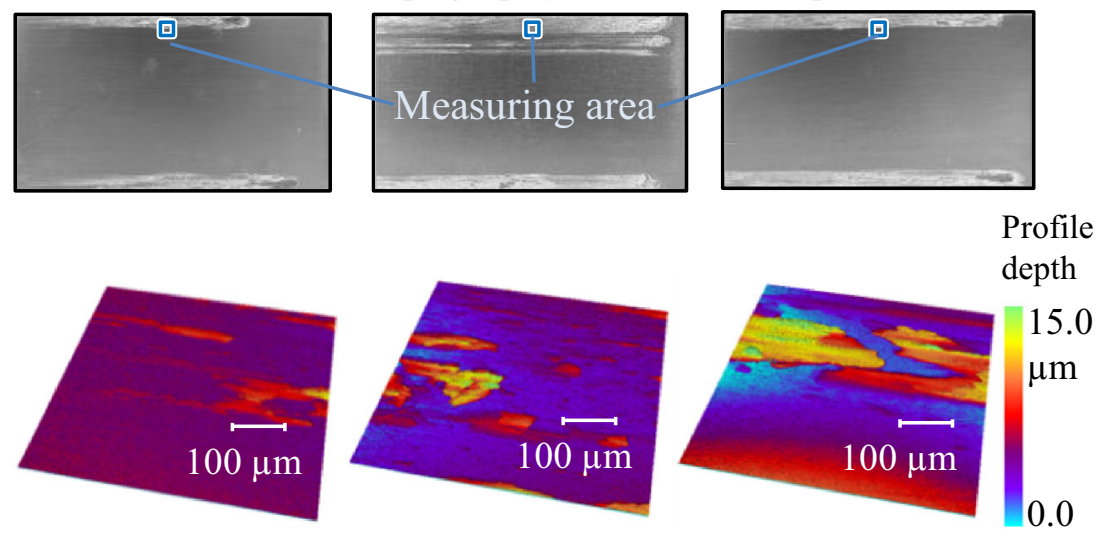

(b) Topography and friction of strip no. 1 after srip drawing test
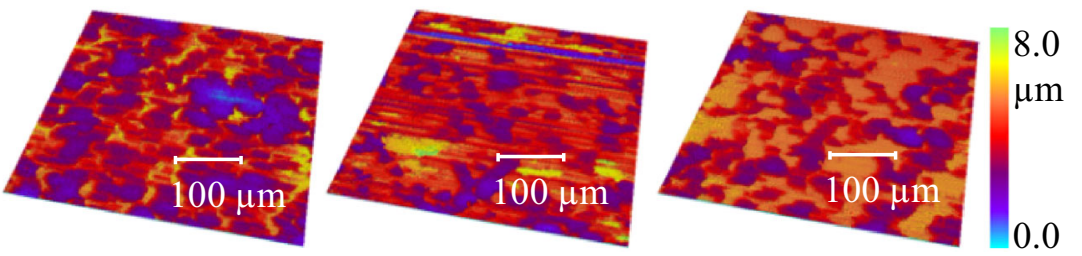

Closed void volume $\mathrm{V}_{\mathrm{cl}}\left(\mathrm{mm}^{2} / \mathrm{m}^{3}\right)$

$$
295+/-31
$$$$
193+/-17
$$

$106+/-9$

Friction coefficient

0.50

0.59

0.61

$$
\begin{array}{ll}
\text { Lens }=20 \mathrm{x} & \text { Alignment }=2^{\text {nd }} \text { degree polynomial } \\
\mathrm{v}_{\text {rel }}=100 \mathrm{~mm} / \mathrm{s} & \mathrm{m}=0 \mathrm{~g} / \mathrm{m}^{2} \quad \mathrm{n}=3
\end{array}
$$

Fig. 8 Surface morphologies after strip drawing tests for friction jaw $\mathbf{a}-\mathbf{f}$ and strip No. $1 \mathbf{g}-\mathbf{i}$ under different normal pressures: a, d, $\mathbf{g} 1.0 \mathrm{MPa}$; b, e, h $1.5 \mathrm{MPa} ; \mathbf{c}, \mathbf{f}, \mathbf{i} 2.0 \mathrm{MPa}$

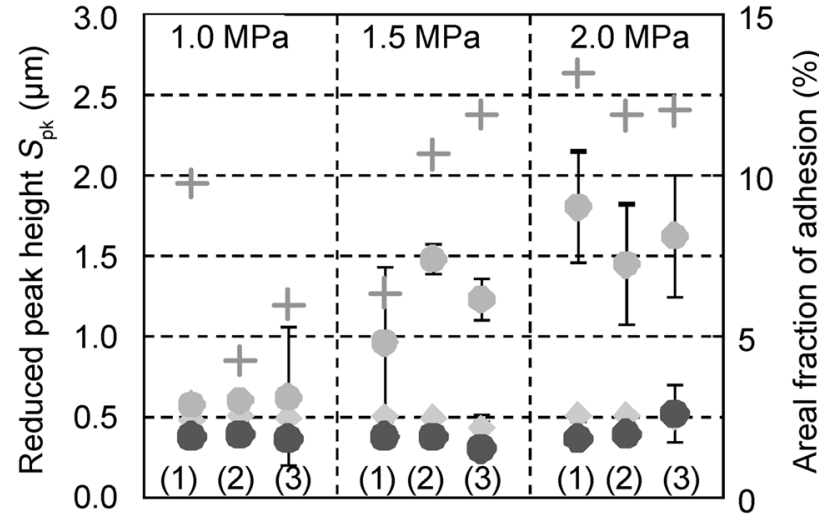

(1) $v_{\mathrm{rel}}=50 \mathrm{~mm} / \mathrm{s} \quad S_{\mathrm{pk}}$, before test

(2) $v_{\text {rel }}=100 \mathrm{~mm} / \mathrm{s} \quad-S_{\mathrm{pk}}$, after test, central area

(3) $v_{\mathrm{rel}}=150 \mathrm{~mm} / \mathrm{s} \quad-S_{\mathrm{pk}}$, after test, edge area

+ Areal fraction of adhesion

Fig. 9 Reduced peak height $\left(S_{\mathrm{pk}}\right)$ of tool surface and areal fraction of adhesion for dry tests microscope shows a good overall correlation with the macro scale measuring by photograph. Again, like for the development of friction coefficients, a varying drawing velocity seems to have no influence on wear mechanisms under dry conditions.

\section{Conclusion and Outlook}

Within this study, the parameters influencing the friction development under lubricated and dry conditions were investigated. As expected, the lubricational conditions have a major influence on the friction. The absence of lubrication leads to entirely changed tribological conditions. Therefore, the well-known influence of process parameters on friction and wear behavior cannot be transferred from lubricated to dry systems. Hence, varying drawing velocities and contact pressures were analyzed. For the lubricated tests, an 
increasing drawing velocity leads to increasing friction coefficients at the investigated levels of contact pressure. Under dry conditions, a changing velocity has no considerable influence on the friction coefficient. Matuszak et al. [11] have figured out in their investigations with low-carbon steel sheet that the relative velocity has an even higher impact on the friction than a variation of lubrication conditions between dry and lubricated. However, this could not be proofed within this investigation. In this study, the velocity has an influence when applying lubricated strips but not under dry conditions. Reason for these differing results might be at the one hand a different level of velocity of $0.2-8 \mathrm{~mm} / \mathrm{s} \mathrm{com-}$ pared to $50-150 \mathrm{~mm} / \mathrm{s}$ and the diverse type of sheet materials. Typical punch speeds are in the range of $100 \mathrm{~mm} / \mathrm{s}$ in industrial applications [12]. Therefore, the practical use of results in [11] is questionable at the investigated velocities. Evaluating the influence of contact pressure, the effect of increasing pressure under dry conditions shows a different behavior than in lubricated tests. A higher contact pressure has a positive influence on the friction level under lubricated conditions, because it assures a stable load carrying film. In dry test series, a higher pressure leads to more intense interaction between the roughness peaks of tool and workpiece surfaces. Thus, the friction coefficient slightly increases. Ashrafi et al. [16] have investigated the tribological behavior of nanostructured pure aluminum and aluminum alloys under unlubricated conditions. In accordance with the findings presented in Fig. 9, the results show as well that higher loads cause an increase in the wear rate. The determined level of friction coefficients exceeds the level of 0.57 under dry conditions, which means that deformation occurs locally. The high level of friction and adhesion show the challenges of dry sheet metal forming with AA6014. Aluminum alloys are commonly known for their poor tribological behavior causing adhesion and abrasion as main wear mechanisms [16]. Within this paper, a laboratory test with an open tribological system as in deep drawing processes is used which could prevent abrasion but clearly reveals galling as main reason of wear. The adhesive wear on the friction jaws leads to changing contacting conditions for each drawn strip influencing the area of real contact. For material combinations with such a strong adhesion tendency, the deviation of the test results increases depending on the amount of adhesion. Further studies with supplementary aluminum alloys will be performed in order to investigate if the results for AA6014 are applicable to other dry systems. Due to the much higher friction, the blank holder forces under dry conditions need to be set to a much lower level in order to achieve the same retention forces. For designing a dry drawing process, it has to be considered that higher contact pressure leads to increasing friction. Thus, larger tool radii should be preferred to reduce the normal contact pressures. The main wear mechanism occurring at dry contact between tool steel and aluminum sheets is adhesion. Therefore, adhesion reducing measures should be considered when designing dry forming processes. One approach could be coating of the forming tools to substitute the separating oil film. Some first investigations by Weihnacht et al. [17] and Horiuchi et al. [18] have shown that DLC coatings can be successfully used to increase the deep drawability of selected aluminum alloys under dry conditions. Further strip drawing tests with DLC-coated friction jaws will be performed in order to investigate the possibilities to reduce the impact of galling.

Acknowledgments The authors thank the German Research Foundation (DFG) for supporting the present investigations by funding the SPP 1676 project ME 2043/43-1.

\section{References}

[1] F. Vollertsen, F. Schmidt, Int. J. Precis. Eng. Manuf. Green Technol. 2, 59 (2014)

[2] A. Ghiotti, S. Bruschi, Wear 271, 2454 (2011)

[3] J. Hirsch, T. Al-Samman, Acta Mater. 61, 818 (2013)

[4] S. Kataoka, M. Murakawa, T. Aizawa, H. Ike, Surf. Coat. Technol. 177-178, 582 (2004)

[5] M. Murakawa, S. Takeuchi, Surf. Coat. Technol. 163-164, 561 (2003)

[6] J. Coello, V. Miguel, A. Martinez, F.J. Avellaneda, A. Calatayud, Wear 305, 129 (2013)

[7] C.J. Kuwer (2007) Dissertation, RWTH Aachen, Berichte aus der Produktionstechnik 22

[8] D.K. Karupannasamy, J. Hol, M.B. de Rooij, T. Meinders, D.J. Schipper, Wear 294-295, 296 (2012)

[9] W. Miller, L. Zhuang, J. Bottema, A.J. Wittebrood, P. De Smet, A. Haszler, A. Vieregge, Mater. Sci. Eng. A 280, 37 (2000)

[10] M. Meiler, H. Jaschke, Adv. Mater. Res. 6-8, 551 (2005)

[11] A. Matuszak, J. Mater. Process. Technol. 106, 250 (2000)

[12] A. Birkert, S. Haage, M. Straub, Umformtechnische Herstellung Komplexer Karosserieteile (Springer, Berlin, 2013)

[13] B.N.J. Persson, Sliding Friction-Physical Principles and Applications (Springer, Berlin, 2000)

[14] Z.G. Wang, Y. Yoshikawa, T. Suzuki, K. Osakada, CIRP Ann. Manuf. Technol. 63, 277 (2014)

[15] A. Vencl, I. Bobic, B. Stojanovic, Ind. Lubr. Tribol. 66, 66 (2014)

[16] H. Ashrafi, M.H. Enayati, R. Emadi, Acta Metall. Sin. (Engl. Lett.) 28, 83 (2015)

[17] V. Weihnacht, A. Brückner, S. Bräunling, Vakuum Forschung und Praxis 20, 6 (2008)

[18] T. Horiuchi, S. Yoshihara, Y. Iriyama, Wear 286-287, 79 (2012) 